\title{
Point observations of liquid water content in wet snow - investigating methodical, spatial and temporal aspects
}

\author{
F. Techel and C. Pielmeier \\ WSL Institute for Snow and Avalanche Research SLF, 7260 Davos, Switzerland \\ Received: 22 September 2010 - Published in The Cryosphere Discuss.: 12 October 2010 \\ Revised: 30 March 2011 - Accepted: 13 May 2011 - Published: 18 May 2011
}

\begin{abstract}
Information about the volume and the spatial and temporal distribution of liquid water in snow is important for forecasting wet snow avalanches and for predicting melt-water run-off. The distribution of liquid water in snow is commonly estimated from point measurements using a "hand" squeeze test, or a dielectric device such as a "Snow Fork" or a "Denoth meter". Here we compare estimates of water content in the Swiss Alps made using the hand test to those made with a Snow Fork and a Denoth meter. Measurements were conducted in the Swiss Alps, mostly above tree line; more than 12000 measurements were made at 85 locations over 30 days. Results show that the hand test generally over estimates the volumetric liquid water content. Estimates using the Snow Fork are generally $1 \%$ higher than those derived from the Denoth meter. The measurements were also used to investigate temporal and small-scale spatial patterns of wetness. Results show that typically a single point measurement does not characterize the wetness of the surrounding snow. Large diurnal changes in wetness are common in the near-surface snow, and associated changes at depth were also observed. A single vertical profile of measurements is not sufficient to determine whether these changes were a result of a spatially homogeneous wetting front or caused by infiltration through pipes. Based on our observations, we suggest that three measurements at horizontal distances greater than $50 \mathrm{~cm}$ are needed to adequately characterize the distribution of liquid water through a snowpack. Further, we suggest a simplified classification scheme that includes five wetness patterns that incorporate both the vertical and horizontal distribution of liquid water in a snowpack.
\end{abstract}

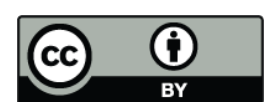

Correspondence to: $\mathrm{F}$. Techel (techel@slf.ch)

\section{Introduction}

The distribution and amount of liquid water in snow affects surface albedo (Warren and Wiscombe, 1985; Gupta et al., 2005), snow stability (e.g. Armstrong, 1976; Kattelmann, 1985; Conway and Raymond, 1993), and is important for forecasting the onset of melt-water run-off (Jones et al., 1983) and reservoir management (Kattelmann and Dozier, 1999).

In Switzerland, most snowpack information comes from snow profiles measured by researchers, avalanche professionals, and observers from the Swiss snow observation network. Measurements are made at flat study plots as well as on potential avalanche slopes with different elevations and aspects. Typically about 1000 snow profiles (mostly in dry snow) are collected each year, and used by the avalanche warning service as input to the national avalanche hazard forecast (Schweizer and Wiesinger, 2001). Liquid water content is typically estimated by conducting "hand" tests for each stratigraphic snow layer according to Swiss and international observational guidelines (WSL, 2008; Fierz et al., 2009, Table 1). In this test, a sample is squeezed by hand, and the water content is estimated by observing its response (Table 1). A magnifying lens can also be used to detect the presence/absence of liquid water. Measurements of snow temperature can also be used to determine the presence/absence of water; snow is expected to be dry at temperatures less than $0^{\circ} \mathrm{C}$. However, estimating liquid water content is difficult even for experienced observers (Martinec, 1991b; Fierz and Föhn, 1994), partly because water flow through snow varies both spatially and temporally (e.g. Colbeck, 1979; Marsh, 1988; Conway and Benedict, 1994).

Our objectives in this study are threefold: (i) investigate the reliability of point observations in relation to temporal and small-scale spatial variability; (ii) compare measurements using the hand test with other measurements

Published by Copernicus Publications on behalf of the European Geosciences Union. 
Table 1. Hand test for the qualitative estimation of liquid water content (mWC) and the approximate range of liquid water content $(\theta)$. The detailed description is taken from the International Classification of Seasonal Snow on the Ground (Fierz et al., 2009, p. 8). This classification is also used in Swiss observational guidelines (WSL, 2008). Half index classes may also be used. $t_{\mathrm{S}}-$ snow temperature.

\begin{tabular}{|c|c|c|c|}
\hline $\begin{array}{l}\text { Wetness } \\
\text { Content }\end{array}$ & $\begin{array}{l}\text { Index } \\
(\mathrm{mWC})\end{array}$ & Description & $\begin{array}{l}\theta \\
{[\text { vol. \%] }}\end{array}$ \\
\hline Dry & 1 & $\begin{array}{l}t_{\mathrm{S}} \leq 0.0^{\circ} \mathrm{C} \text {. Disaggregated snow grains have little tendency } \\
\text { to adhere to each other when pressed together. }\end{array}$ & 0 \\
\hline Moist & 2 & $\begin{array}{l}t_{\mathrm{S}}=0.0^{\circ} \mathrm{C} . \text { The water is not visible, even at } 10 \times \text { magnification. } \\
\text { When lightly crushed, the snow has a tendency to stick together. }\end{array}$ & $0-3$ \\
\hline Wet & 3 & $\begin{array}{l}t_{\mathrm{S}}=0.0^{\circ} \mathrm{C} \text {. The water can be recognized at } 10 \times \text { magnification } \\
\text { by its meniscus between adjacent snow grains, but water cannot } \\
\text { be pressed out by moderately squeezing the snow in the hands. }\end{array}$ & $3-8$ \\
\hline Very Wet & 4 & $\begin{array}{l}t_{\mathrm{S}}=0.0^{\circ} \mathrm{C} \text {. The water can be pressed out by moderately } \\
\text { squeezing the snow in the hands, but an } \\
\text { appreciable amount of air is confined within the pores. }\end{array}$ & $8-15$ \\
\hline Soaked & 5 & $\begin{array}{l}t_{\mathrm{S}}=0.0^{\circ} \mathrm{C} . \text { The snow is soaked with water and } \\
\text { contains a volume fraction of air from } 20 \text { to } 40 \% \text {. }\end{array}$ & $>15$ \\
\hline
\end{tabular}

using dielectric methods; (iii) examine whether wetness observations over larger areas would help improve wet snow avalanche forecasting.

\section{Background}

\subsection{Liquid water in snow}

Liquid water is introduced to snow by rain and/or melt. Melting at the surface depends primarily on the incoming flux of shortwave radiation, which varies with slope aspect and elevation. The advance of a wetting front into snow is seldom uniform; even under controlled laboratory conditions it is difficult to achieve a homogeneous distribution (Brun, 1989). Infiltration usually starts through isolated small "flow fingers" (Marsh, 1988; Schneebeli, 1995; Waldner et al., 2004), which enlarge into channels with increased time and flow (Kattelmann and Dozier, 1999). The pattern and timing of infiltration depends on snow structure, temperature, slope angle and the amount of liquid water entering the snowpack (Conway and Benedict, 1994; Fierz and Föhn, 1994). Gravitational forces usually dominate infiltration, although layerparallel infiltration is often observed above impermeable ice layers, or capillary barriers that consist of fine grains layers of coarse grains (Wankiewicz, 1979; Jordan, 1994; Waldner et al., 2004). Introduction of liquid water into snow leads to rapid changes in grain shape (Brun, 1989; Coléou and Lesaffre, 1998), grain coarsening (Raymond and Tusima, 1979; Brun, 1989; Marsh, 1987) and an increase in bulk density (Colbeck, 1997; Marshall et al., 1999; Jordan et al., 2008). Important feedback mechanisms exist between snow meta- morphism, hydraulic conductivity and water flow (Jordan et al., 2008). The amount of liquid water influences the mechanical properties of snow. Relatively small amounts of liquid water can reduce the strength of snow; Techel et al. (2011) found that the strength of temperature-gradient snow (such as facets or depth hoar) decreased significantly at low water contents $(\theta<3$ vol. \%), while Colbeck (1982) described loss in strength of seasonal snow at approximately 8 vol. $\%$.

\subsection{Estimation and measurement of liquid water in snow}

Liquid water content of snow has been measured by centrifugal separation, melting calorimetry, freezing calorimetry, alcohol calorimetry and the dilution method. These methods, which are summarized by Stein et al. (1997), are difficult to perform and time-consuming, which makes them impractical for operational forecasting. Liquid water content has also been estimated by measuring the real and imaginary parts of the permittivity of snow. This measurement is diagnostic of liquid water because the permittivity of water $\left(\epsilon_{i}^{\prime} \approx 86\right)$ is much higher than those of air $\left(\epsilon_{i}^{\prime} \approx 1\right)$, and ice $\left(\epsilon_{i}^{\prime} \approx 3.15\right)$ (Frolov and Macharet, 1999; Louge et al., 1998). In this study, we compare "hand" measurements with measurements made with a "Finnish Snow Fork" (SnF, Sihvola and Tiuri, 1986; Toikka, 2009) and also with a Denoth meter (Dn, Denoth, 1994).

The Snow Fork is a two-pronged wave-guide that operates at $\sim 1 \mathrm{GHz}$ and measures both the real and the imaginary parts of the permittivity simultaneously measuring changes in the resonance curve between air and snow (Fig. 1). 


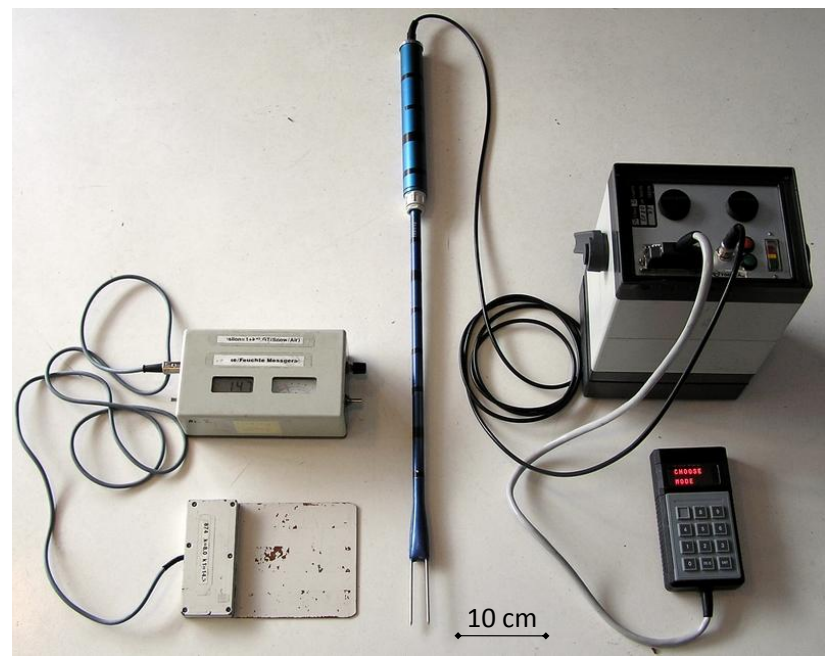

Fig. 1. Denoth (left) and Snow Fork (right) measurement devices.

Insertion of the Snow Fork compresses the surrounding snow, which increases snow density by approximately $1-$ $2 \%$, which has a small effect on the estimate of the real part of the permittivity (Sihvola and Tiuri, 1986). The snow fork that we used provided an estimate of water content on samples of area $7.5 \times 2 \mathrm{~cm}^{2}$. The $\mathrm{SnF}$ has been used in a variety of studies including measuring the spatial wetness distribution (Williams et al., 1999), snow characteristics in Antarctica (Kärkäs et al., 2005), and the wetness of snow in ski tracks (Moldestad, 2005).

The Denoth meter is a capacitance probe, which measures the permittivity of snow of area $13 \times 13.5 \mathrm{~cm}^{2}$ (Fig. 1). A separate measurement of density is required to solve for the imaginary part of the permittivity (Denoth, 1994), which is necessary to estimate liquid water content. The Denoth meter has also been used in field studies to monitor changes in snowpack wetness during the melt period (Martinec, 1991a; Kattelmann and Dozier, 1999), and to validate snowpack models (Mitterer et al., 2010).

The accuracy of measurements made by dielectric methods is \pm 0.5 vol. \% (Sihvola and Tiuri, 1986; Fierz and Föhn, 1994). Additional uncertainty can arise if sensors near the surface are affected by solar radiation (Lundberg et al., 2008). These methods are destructive to the snow sample and also require the excavation of a snow-pit, which can cause local disturbances to water flow (Fig. 2). More recently, nondestructive measurement methods like the Snow Pack Analyser (Mess-Systemtechnik, 2010) and ground-penetrating radar installed upward-looking at the snow-ground interface have been applied to measure snow wetness (Heilig et al., 2009). In addition, multispectral imaging from satellites has been used successfully to map regions of dry and wet snow surfaces (e.g. Gupta et al., 2005).

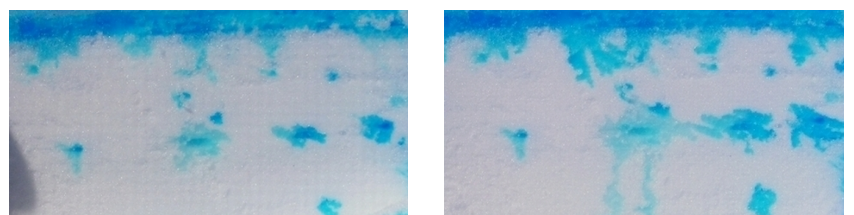

Fig. 2. Response of water flow in a slope. Shown are $50 \mathrm{~cm}$ wide frontal views of the pit-wall facing down-slope in experiments using dye-tracers. The left photo was taken immediately after cutting a pit-wall, the right picture approximately $30 \mathrm{~s}$ later. The size of the wet area at the pit-wall increased rapidly due to water flowing from lateral flow channels into the pit-wall.

\section{Scope and aim}

To address the three objectives of this study, we designed a series of measurements to investigate the following specific questions:

1. Does the "hand" test provide a realistic point estimate of water content in snow?

2. How do layer characteristics such as hardness, grain shape or size, influence the results from the "hand" test?

3. Can comparable measurements of snowpack wetness be achieved by either measuring before digging a snow pit or at the side-wall of a snow profile?

4. Is it necessary to consider small-scale spatial variability in water content when interpreting wetness profiles?

Based on the answers to these questions we developed a robust sampling strategy for field measurements. For practical purposes, we introduced a simplified snow wetness classification, which incorporates information on vertical and horizontal wetness distribution.

\section{Methods and data}

Most of the data analyzed was collected in winter and spring 2008/2009 and spring 2009/2010 in Alpine terrain in Switzerland in the Fribourg and Western Bernese Alps and Pre-Alps, the region of Davos and in the Lower Engadin (Fig. 3). The majority of these observations were carried out in potential avalanche terrain (slopes steeper than $30^{\circ}$ ) above tree-line. The data-set includes only one day when observations followed a rain-on-snow event (less than $5 \mathrm{~mm}$ precipitation fell as rain). 


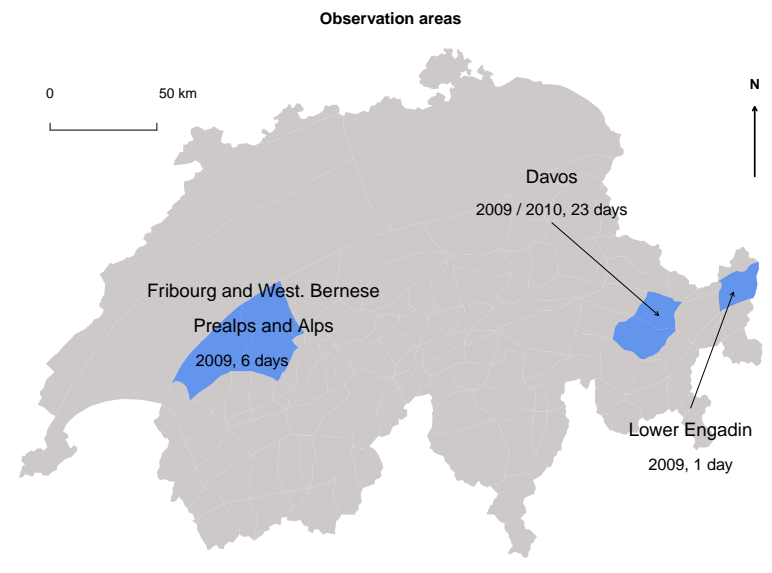

Fig. 3. Map showing Switzerland (grey) and the regions (blue), where measurements were conducted in 2009 and 2010. The number of days is shown, when measurements were carried out. The majority of measurements were taken in the region surrounding Davos.

\subsection{Field methods}

All measurements were carried out in seasonal snow. Our plan was to sample data that were representative of diverse topographic, snowpack and wetness conditions. Slope selection was dictated by safety concerns, as many observations were carried out during periods of wet snow avalanche activity.

In 2008/2009, we focused on measuring diurnal changes in wetness and comparing results from hand tests with dielectric measurements. Measurements were carried out in the morning and repeated in the afternoon in the same slope at a distance of approximately 3-5 m. Wetness content $\theta$ was first measured horizontally (Fig. 4a), these were followed by the excavation of a snow-pit and measurements made on a shaded side-wall of the snow-pit (Fig. 4b). Lastly, a manual snow profile including measurements of layer thickness, hardness, wetness, grain shape and size was recorded according to observational guidelines (WSL, 2008; Fierz et al., 2009). Snow temperatures were measured using a calibrated, digital thermometer with an accuracy of $\pm 0.5^{\circ} \mathrm{C}$ (Milwaukee Stick Thermometer TH310). Snow stability during this period is discussed in detail by Techel and Pielmeier (2009).

During the 2009/2010 winter we focused on measuring changes in snow wetness over several days and the distribution of water within the vicinity of a snow profile recorded according to Swiss observational guidelines. $\theta$ was usually measured by inserting the Snow Fork vertically into the snow in cross-sections of up to $5 \mathrm{~m}$ width. These measurements were followed by a manual snow profile and a snowpack stability test. A qualitative estimation of liquid water content (mWC) was part of the standard observation procedure in all manual snow-profiles (WSL, 2008; Fierz et al., 2009, Ta-
Table 2. Spacing and extent of measurement lay-outs as shown in Fig. 4 (concept according to Blöschl, 1999). x-direction corresponds to horizontal distance, $y$-direction is distance between consecutive measurements as in Fig. $4 \mathrm{a}$, and z-direction is equivalent to snow depth measured vertically (in $\mathrm{cm}$, Fig. $4 \mathrm{~b}, \mathrm{c}$ ).

\begin{tabular}{|c|c|c|c|c|}
\hline mode & $\begin{array}{l}\text { extent } \\
{[\mathrm{cm}]}\end{array}$ & $\begin{array}{r}\text { spacing } \\
\mathrm{X} \\
{[\mathrm{cm}]}\end{array}$ & $\begin{array}{r}\mathrm{y} \\
{[\mathrm{cm}]}\end{array}$ & $\begin{array}{r}\mathrm{Z} \\
{[\mathrm{cm}]}\end{array}$ \\
\hline profile & 40 & 20 & - & 5 \\
\hline profile & 300 & 10 & - & 5 \\
\hline horizontal & 40 & 20 & 5 & - \\
\hline vertical & 500 & 50 & - & 5 \\
\hline
\end{tabular}

ble 1), the Finnish Snow Fork was used to obtain a more quantitative measure of liquid water content while the Denoth meter was used to allow a comparison between the two instruments.

\subsubsection{Sampling design for liquid water content measurements in a natural snowpack with the Snow Fork}

Liquid water content was measured in one of the following three ways:

- horizontal - These measurements preceded all slope profiles. Three contiguous measurements spaced $20 \mathrm{~cm}$ apart (across the slope) with horizontal measurement intervals of $5 \mathrm{~cm}$ into the snowpack were conducted (Fig. 4a, Table 2).

- profile - These measurements accompanied all slope profiles. Measurements were undertaken on the sidewall of a manual snow profile. Measurements were slope- and layer-parallel, and generally less than $50 \mathrm{~cm}$ from horizontal measurements. Vertical measurement intervals were $5 \mathrm{~cm}$ and the distance between the three measurement rows was $20 \mathrm{~cm}$ (Fig. 4b, Table 2).

- vertical - These measurements were conducted to determine the spatial variability of water content. The vertical distance between consecutive measurements was $5 \mathrm{~cm}$, the horizontal distance (across the slope) $50 \mathrm{~cm}$ (Fig. 4c, Table 2).

Applying the concept from Blöschl (1999), measurement spacing and extent are shown in Table 2. The support, the integrated volume of a measurement device (Blöschl, 1999), is approximately $47 \mathrm{~cm}^{3}$ for the Snow Fork (Moldestad, 2005).

The idea behind horizontal measurements was to minimize the possibility of water flow in front of the probe. This strategy, together with the fast measuring speed of the Snow Fork (it typically took less than 2 min to measure one vertical profile consisting of 15 single measurements) minimized this 

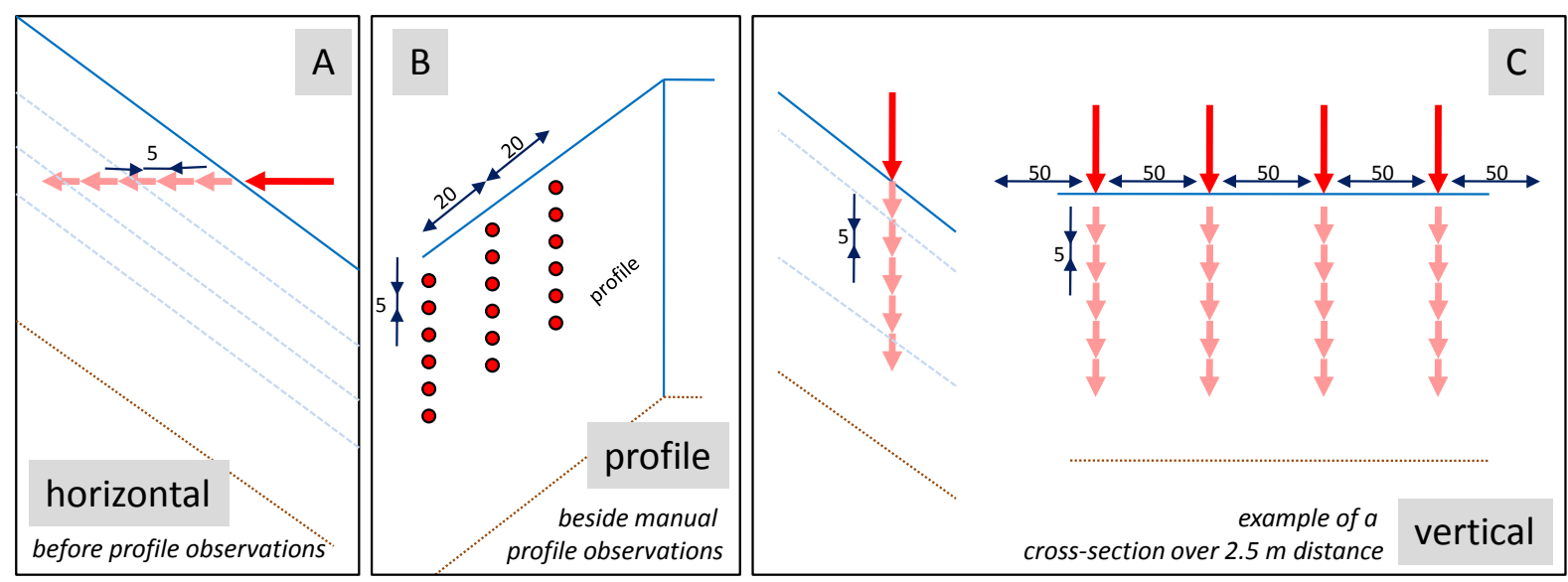

Fig. 4. Liquid water content measurements: sampling design for horizontal, profile and vertical measurements. (A) horizontal measurements in $5 \mathrm{~cm}$ steps to a depth of $75 \mathrm{~cm}$. (B) observations adjacent to manual snow profile, vertical distance $5 \mathrm{~cm}$, slope-parallel distance $20 \mathrm{~cm}$. (C) vertical measurements for spatial variability observations, measurement steps $5 \mathrm{~cm}$, horizontal distance $50 \mathrm{~cm}$. Refer also to Table 2 for extent and spacing of measurements.

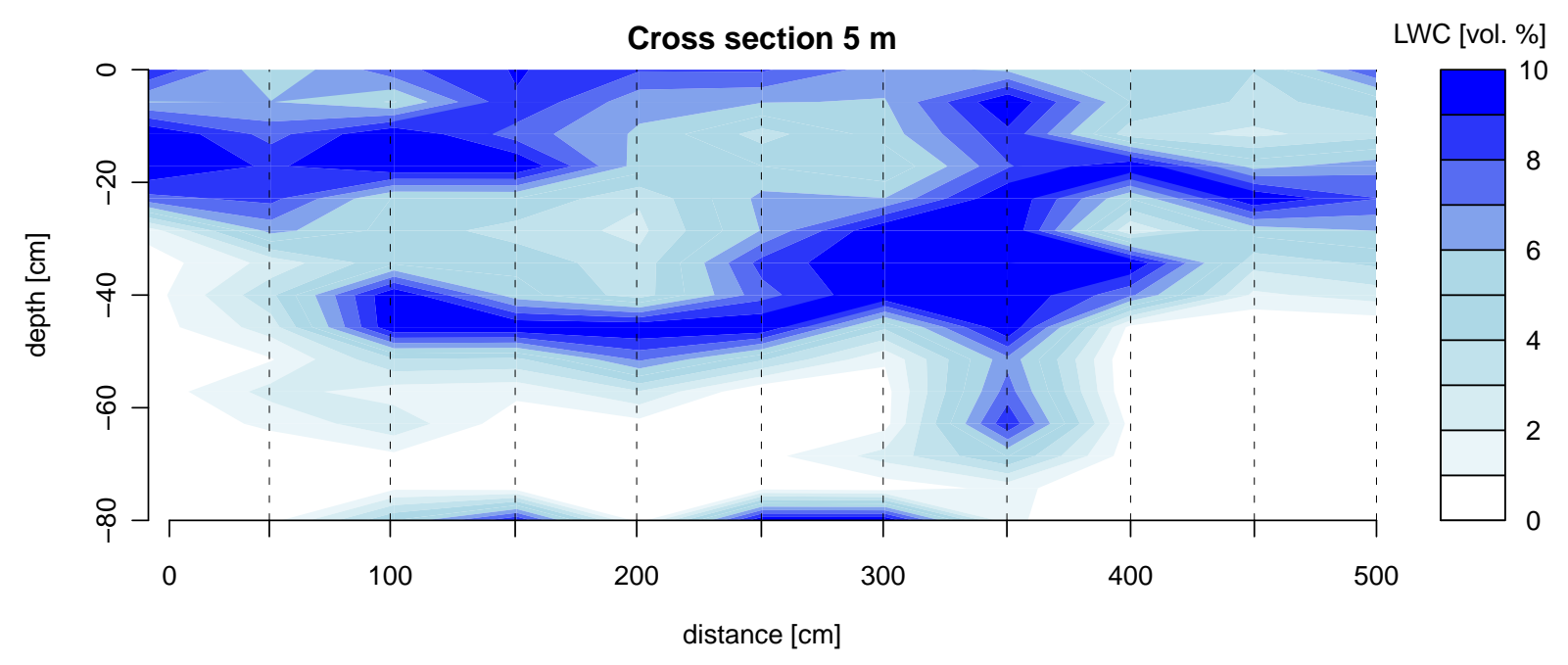

Fig. 5. Contour plot showing cross-section of snow wetness $(\theta)$ to a depth of $80 \mathrm{~cm}$ over $5 \mathrm{~m}$ wide areas across the slope. Measurements were conducted at horizontal intervals of $50 \mathrm{~cm}$ (lines) with a vertical spacing of $5 \mathrm{~cm} .4$ April 2009, S aspect, $2660 \mathrm{~m}, 30^{\circ}$. $\theta$, measured with the Snow Fork, is corrected by -0.8 vol. \% (this corresponds to the median offset in dry snow).

potential problem. As shown in Fig. 5, there was usually a clear distinction between wet to dry layers indicating that water running ahead of the $\mathrm{SnF}$ was not a problem.

\subsubsection{Comparison of Denoth wetness meter and Snow Fork device}

Adjacent measurements from the Denoth meter (2-3 measurements) were compared with measurements from the Snow Fork (2-6 measurements). The measurements were always undertaken on a sidewall of snow pits and parallel to the layer stratigraphy. Horizontal and vertical distances between measurements was $5 \mathrm{~cm}$. Snow densities were sampled directly above and below the Denoth meter measurements using a $100 \mathrm{~cm}^{3}$ density cutter and a digital scale.

\subsection{Data}

Snow wetness was measured using the Snow Fork in more than 80 different locations in a variety of measurement designs and wetness conditions in natural snow.

Measurements in 2008/2009 targeted small-scale variability (within $40 \mathrm{~cm}$ ), diurnal changes in wetness within the same slope and compared hand and dielectric estimates of snow wetness. More than 7000 measurements were taken 
Table 3. Data overview: shown are the number of days $\left(n_{\text {day }}\right)$, locations $\left(n_{\text {loc }}\right)$, measurement depths $\left(n_{\text {depth }}\right)$ and single measurements $(n)$ for the various measurement modes (Fig. 4) using the Snow Fork $(\mathrm{SnF})$, and for the comparison between $\mathrm{SnF}$ and Denoth instrument (Dn).

\begin{tabular}{lrrr}
\hline mode & $\begin{array}{r}n_{\text {day }} \\
\left(n_{\text {loc }}\right)\end{array}$ & $n_{\text {depth }}$ & $n$ \\
\hline horizontal & $24(60)$ & $>1300$ & $>3500$ \\
profile & $26(63)$ & $>1200$ & $>3500$ \\
vertical & $10(26)$ & 330 & $>3500$ \\
Dn-SnF comparison & $8(11)$ & 134 & $251-637$ \\
\hline
\end{tabular}

accompanying manual snow profiles using the horizontal (Fig. 4a) and profile measuring modes (Fig. 4b, Table 3). These were recorded in more than 2500 different measurement depths or layers.

In spring 2010, the focus was on investigating the wetness variability at spatial scales of up to $5 \mathrm{~m}$. Vertical measurements (Fig. 4c) were carried out in 25 locations. The comparison of Snow Fork and Denoth instrument is based on measurements in 134 different snow layers made in profile mode (Table 3 ).

\subsection{Data analysis}

The water content measured with the Snow Fork $\left(\theta_{\mathrm{SnF}}\right)$ ranged from 0 to 23.6 vol. \%. According to the Snow Fork manual (Toikka, 2008), measurements with $\theta_{\mathrm{SnF}}>10$ vol. \% may not be accurate. However, as these values often corresponded to areas of high snowpack wetness, they were not excluded from analysis but considered as $10 \mathrm{vol} . \%$. The calculation of the water content using the Denoth instrument $\left(\theta_{\mathrm{Dn}}\right)$ requires a measurement of snow density $\rho$. We used the mean of two measurements adjacent to the dielectric measurement.

The relationship between estimated water content (wetness index, mWC) and measured liquid water content $\left(\theta_{\mathrm{SnF}}\right)$ used the conversion shown in Table 1 . If $\theta_{\mathrm{SnF}}$ was within \pm 0.5 vol. $\%$ of a class limit, this is considered as an intermediate (half) index class and not considered as a false classification or measurement. Snow wetness was often nonnormally distributed. Therefore, the median and the interquartile range are considered as robust measures of central tendency and data distribution. If several measurements are available the median $\theta$ is used. Linear regression models were derived for $\theta$ and the Pearson coefficient of determination $r^{2}$ was calculated. For categorical variables (mWC), the Spearman correlation $r_{\mathrm{s}}$ was used. Data was tested for significant differences using non-parametric tests (Mann Whitney U-test, Kruskal-Wallis H-test, sign-test, Crawley, 2007), the level of significance $\alpha \leq 0.05$. Linear interpolation is ap- a)
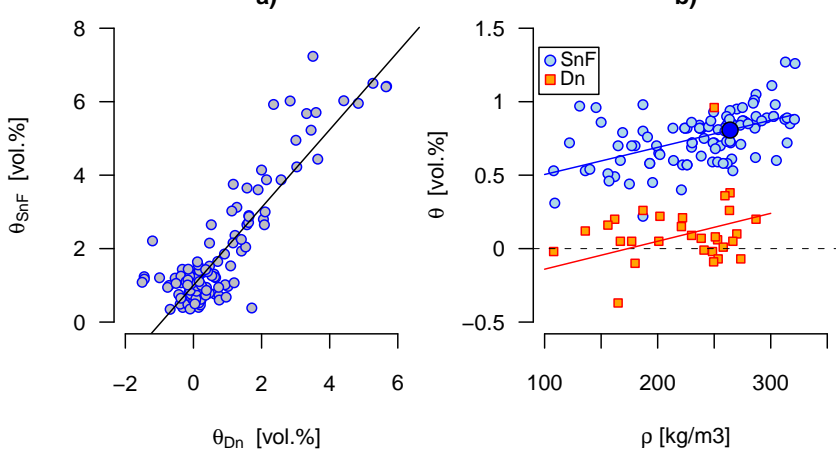

Fig. 6. Comparison of measured liquid water content using the Denoth $\left(\theta_{\mathrm{Dn}}\right)$ and the Snow Fork $\left(\theta_{\mathrm{SnF}}\right)$ instruments in (a) all wetness conditions $(n=134)$ and in (b) in dry snow as a function of snow density $(\rho)$. Linear regression models are shown in both plots. The median off-set of the $\theta_{\mathrm{SnF}}$ for the dry snow data is marked by the dark-blue dot $\left(\rho=250 \mathrm{~kg} \mathrm{~m}^{3}, \theta_{\mathrm{SnF}}=0.8\right.$ vol. $\left.\%\right)$.

plied in the contour plots (as in Fig. 5) and is described in the R-package graphics (R, 2009).

\section{Results}

\subsection{Liquid water content measurements using Snow Fork and Denoth wetness instrument}

In a variety of snow wetness situations, the liquid water content measured with the Snow Fork $\left(\theta_{\mathrm{SnF}}\right.$, in vol. \%) is generally higher than with the Denoth meter $\left(\theta_{\mathrm{Dn}}\right.$, Fig. 6a), but the measurements were strongly correlated:

$\theta_{\mathrm{SnF}} \approx 1.06 \times \theta_{\mathrm{Dn}}+1.0 \quad\left(r^{2}=0.78, p \leq 0.001\right)$

Our results are similar to previous studies (Denoth, 1994; Williams et al., 1999; Frolov and Macharet, 1999). The variability between adjacent measurements was similar regardless which instrument was used.

In dry snow (hand test dry and snow temperature $\leq$ $-0.5^{\circ} \mathrm{C}$ ), we investigated the effect of snow density $(\rho)$ on the measured water content. The Snow Fork recorded a median $\theta_{\mathrm{SnF}}=0.8$ vol. $\%$ (standard deviation $\sigma=0.2$ vol. $\%$, $\left.n_{\mathrm{SnF}}=487\right)$. The Denoth wetness device showed lower values $\theta_{\text {Dn }}=0.1 \mathrm{vol} . \%\left(\sigma=0.17 \mathrm{vol} . \%, n_{\mathrm{Dn}}=281\right)$. Measured water content in dry snow was generally 0.65 vol. \% higher using the Snow Fork than with the Denoth meter (Fig. 6b). In dry snow poor positive correlations between $\theta$ and $\rho$ were observed:

$\theta_{\mathrm{SnF}}=0.0019 \rho+0.32 \quad\left(r^{2}=0.28, p<0.001\right)$

$\theta_{\text {Dn }}=0.0019 \rho-0.33 \quad\left(r^{2}=0.11, p<0.05\right)$ 


\subsection{Influence of sampling design}

Liquid water content measurements made before digging a snow-pit (horizontal mode, Fig. 4a) and following manual snow profile observations (profile mode, Fig. 4b) were compared in 86 locations.

No significant difference between either mode of measuring the water content was noted in locations with low water content (median $\theta_{\mathrm{SnF}}<1.3 \mathrm{vol} \%$, dry or barely moist snow). In moist and wet snow $\left(\theta_{\mathrm{SnF}} \geq 1.3 \mathrm{vol} \%\right)$, horizontal measurements were wetter than the measurements at the sidewall following snow pit excavation $(p=0.03)$. However, the median difference $(\theta=0.43 \mathrm{vol} . \%)$ is within the range of measurement uncertainty ( $\pm 0.5 \mathrm{vol} . \%$, Sihvola and Tiuri, 1986; Fierz and Föhn, 1994).

In our data-set, $2 \%$ of the recorded values were higher than 10 vol. \%. These high values were more frequently observed when we measured across layer boundaries in an undisturbed snowpack before digging the snow-pit than in layer-parallel measurements taken at the sidewall of a snow profile. In horizontal measurements, $\theta$-values greater than 10 vol. \% occur more frequently in layers relatively close to the snow surface and when neighboring measurements also showed high values.

\subsection{Qualitative snow profile observations in wet snow}

Manually estimated water content (mWC) and liquid water content $\left(\theta_{\mathrm{SnF}}\right)$ were compared in 314 layers. $\mathrm{mWC}$ and $\theta_{\mathrm{SnF}}$ were strongly correlated $\left(r_{\mathrm{s}}=0.73, p \leq 0.001\right)$. Correctly estimated water content $\mathrm{mWC}$ decreased with increasing $\theta_{\mathrm{SnF}}$ (Fig. 7a, b). These results are similar to an earlier study (Martinec, 1991b). Both, Martinec (1991b) and our results, show that dry layers are normally well described, while wetter layers are often incorrectly classified (30\% in our study for wet layers). It is of note, however, that few measurements were done in snow with $\theta_{\mathrm{SnF}}>8$ vol. $\%$. Very few layers were estimated as being very wet. In these layers, mWC was always overestimated.

The wetness in layers consisting of coarse melt-freezeparticles (MF, snow class MF, Fierz et al., 2009) is more frequently falsely estimated (33\% of cases) than in layers consisting of fine precipitation particles and snow which has undergone low-temperature gradient metamorphism (LTG, snow classes PP, DF, RG, $13 \%$ ) or coarse medium to high temperature gradient metamorphosed grains (TG, snow classes FC, DH, $13 \%$ ). No significant correlation was observed between snow hardness and the correct estimation of the water content. The wetness range in MF is much greater than in LTG or TG layers (MF: $0-10$ vol. \%; LTG/TG: $0-$ 5.5 vol. $\%)$. $\theta_{\mathrm{SnF}}>3$ vol. $\%$ is more frequently observed in MF ( $>20 \%$ of cases) and rarely in LTG/TG $(<4 \%$ cases). LTG layers estimated as being wet were almost always overestimated. The error rate in snow estimated as being wet is smallest in TG snow $(20 \%)$.
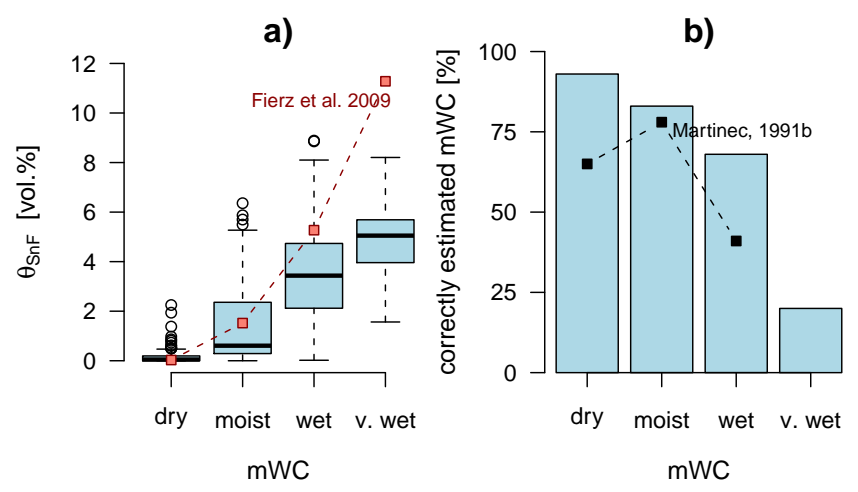

Fig. 7. (a) Box-plot comparing estimated liquid water content $(\mathrm{mWC})$ and water content measured with the Snow Fork $\left(\theta_{\mathrm{SnF}}\right.$, $n=318,4$ observers). As comparison the mean for each class is shown based on the conversion given in Fierz et al. (2009). (b) shows the frequency that mWC was correctly estimated (light blue bars). For comparison, data by a previous study is shown (black dashed line, black squares Martinec, 1991b, $n=518,9$ observers). $\theta_{\mathrm{SnF}}$ is corrected by -0.8 vol. $\%$ (this corresponds to the median offset in dry snow).

Hardness of snow is influenced by the liquid water content. This can be observed by comparing the hardness (hand hardness test, Fierz et al., 2009) with estimated and measured water content. A negative correlation exists in layers classified as MF $\left(r_{\mathrm{s}}=-0.70\right.$ for $\mathrm{mWC}, r_{\mathrm{s}}=-0.43$ for $\theta_{\mathrm{SnF}}$, $p \leq 0.001$ ). Not surprisingly, the transition from dry (frozen) to wet infers a significant hardness decrease. While no clear trend was observed for TG snow, all layers estimated as being wet $(n=6)$, or measured as being wet $\left(\theta_{\mathrm{SnF}}>3 \mathrm{vol} . \%\right.$, $n=9$ ), had a hand hardness of 1 . This was significantly softer than the dry hand hardness $(p \leq 0.01)$ in TG snow.

\subsection{Temporal changes in snow wetness: morning vs. afternoon}

Snowpack wetness was compared in 33 locations between morning and afternoon. Generally, snow wetness increased within the uppermost $10 \mathrm{~cm}$ of the snowpack $(p<0.05$, Fig. 8a). This is not surprising, as measurements were carried out when day-time warming was expected. Analyzing each location individually, the median snowpack wetness (excluding the uppermost $10 \mathrm{~cm}$ ) changed significantly in only nine cases $(p<0.05)$. Surprisingly, six of these nine wetness profiles showed decreasing values (Fig. 8b). These significant changes always involved a transition from dry or barely moist snow (median $\theta_{\mathrm{SnF}}^{\mathrm{m}} \leq 1.3 \mathrm{vol}$. \%, third quartile $\theta_{\mathrm{SnF}}^{\mathrm{q} 3} \leq 1.9$ vol. \%) to moist or wet snow $\left(\theta_{\mathrm{SnF}}^{\mathrm{m}} \geq 1.2\right.$ vol. $\%$, $\theta_{\mathrm{SnF}}^{\mathrm{q} 3} \geq 1.9$ vol. \%) or vice versa (Fig. $8 \mathrm{c}$ ), where both the changes in median and third quartile are significant $(p \leq$ $0.001)$. 

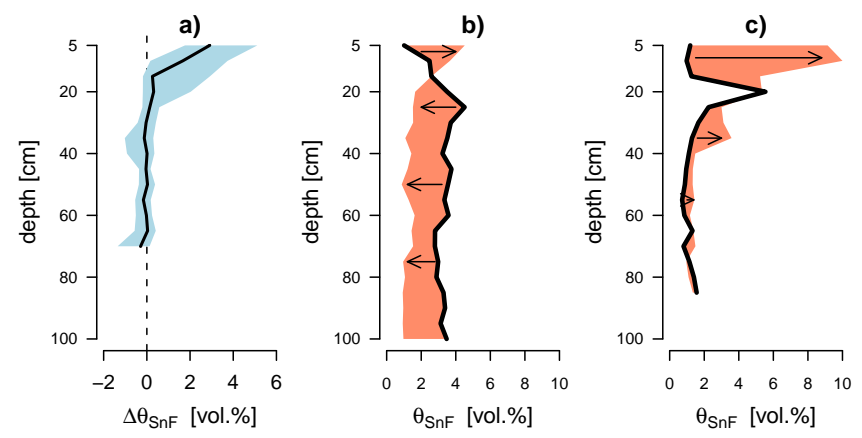

Fig. 8. (a) Difference between morning and afternoon liquid water content $\left(\theta_{\mathrm{SnF}}\right)$, measured in 33 locations. Positive values indicate an increase in $\theta_{\mathrm{SnF}}$ from morning to afternoon. Depth is given in $\mathrm{cm}$ below snow surface. The median is the bold line, the shaded area represents the interquartile range. (b) and (c) example of profiles with significant changes in $\theta_{\mathrm{SnF}}$ during the day. The bold line represents the morning measurements (median of 3), the shaded area and the arrows indicate the change during the day.

We have only one explanation for the profiles where overall water content decreased during the day: the snowpack was in the initial part of the melt-phase with spatially and temporally highly variable water infiltration patterns where both dry and wet regions exist within the snowpack. In such situations it is unclear if morning or afternoon measurements were a better representation of snowpack wetness at the time. Considering just the six observations, where snowpack wetness decreased during the day, almost $20 \%$ of the measurements may be a poor representation of snowpack wetness.

\subsection{Spatial variability in water content distribution}

The variability of liquid water content $\theta_{\mathrm{SnF}}$ was investigated at horizontal distances of $10-500 \mathrm{~cm}$. The difference between $\theta_{\mathrm{SnF}}$ at measurement spacings of 10 and $20 \mathrm{~cm}$ was significantly less than at $40 \mathrm{~cm}$ or greater $(p<0.001)$. In $50 \%$ of the cases variability was similar to, or less than the measurement accuracy $(\theta \pm 0.5 \mathrm{vol} . \%)$. However, even at relatively small horizontal spacings of $20 \mathrm{~cm}, 20 \%$ of the measurements differed by more than 1 vol. $\%$ and $10 \%$ of the measurements differed by more than 1.8 vol. $\%$. Generally the correlation between measurements at various measurement distances was moderate to strong (Fig. 9a). Significant differences between the median $\theta_{\mathrm{SnF}}$ in each vertical column existed in five of the twenty-five $500 \mathrm{~cm}$-wide grids $(p \leq 0.05)$. Variability in $\theta_{\mathrm{SnF}}$ increased marginally with greater measurement spacings (Fig. 9b). The variability (expressed as the interquartile range) as a function to the median water content within $5 \mathrm{~m}$ distance $\left(\theta_{5 \mathrm{~m}}\right)$ is much smaller at $\theta_{5 \mathrm{~m}}<1.3$ vol. $\%$ than at $\theta_{5 \mathrm{~m}} \geq 1.3$ vol. \% $( \pm 0.16$ and \pm 0.52 vol. $\%$, respectively, $p<10^{-16}$, Fig. 9 b, c).

Randomly selecting one single measurement showed strong correlations to the $\theta_{5 \mathrm{~m}}\left(r^{2}>0.83\right)$ with the large

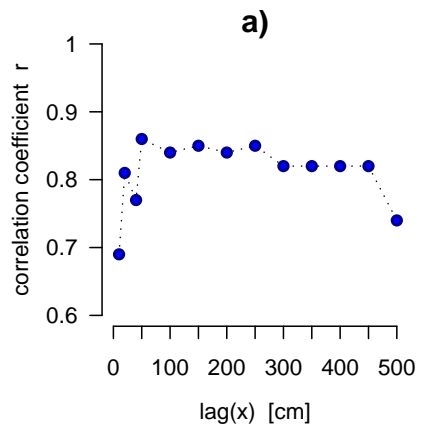

b)
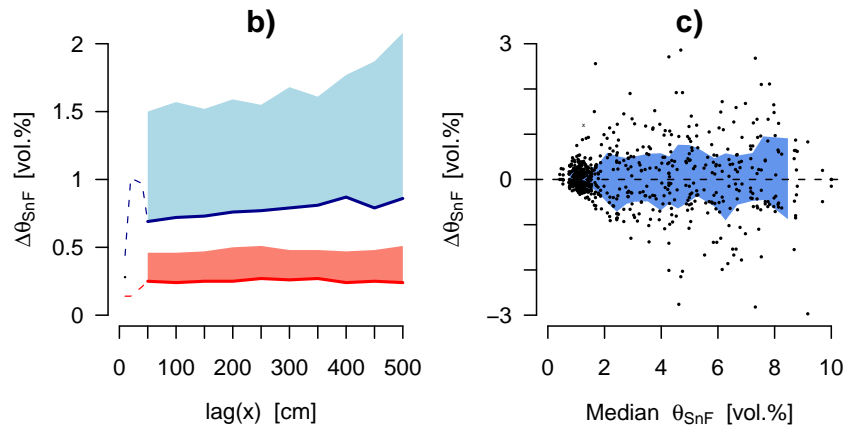

Fig. 9. Variability in measured water content as a function of lagdistance between measurements and water content. (a) Pearson correlation coefficient $r$ for all measurement pairs with the same lag distance $\operatorname{lag}(x)$. (b) Difference in liquid water content $\left(\Delta \theta_{\mathrm{SnF}}\right)$ between measurement pairs at lag distance $(x)$. Compared are the median (bold line) and the range between median and the third quartile for each lag distance (shaded area). The data-set is split into measurements where the median $\theta$ of the measurements taken over $5 \mathrm{~m}$ was less than $1.3 \mathrm{vol} . \%$ (lower values, red) and more than $1.3 \mathrm{vol} . \%$ (higher values, blue). (c) Difference between median water content and the first and third quartile (always measured within $5 \mathrm{~m}$ distance, $\left.\Delta \theta_{\mathrm{SnF}}\right)$. The shaded area highlights the interquartile-range averaged over 25 measurements.

majority of measurements being within 0.5 vol. \% (Table 4 , Fig. 10a, b). In more than $90 \%$ of the cases the measurement was within the same wetness class (as defined in Table 1) (Fig. 10c). The median water content observed in three measurements $\theta_{\mathrm{m} 3}$ at regular intervals of $50 \mathrm{~cm}, 100 \mathrm{~cm}$ or $200 \mathrm{~cm}$ was very strongly correlated to $\theta_{5 \mathrm{~m}}\left(r^{2}>0.93\right) . \theta_{\mathrm{m} 3}$ was in more than $70 \%$ of the cases within $0.5 \mathrm{vol} . \%$ of $\theta_{5 \mathrm{~m}}$ and in more than $98 \%$ within $\pm 0.5 \mathrm{mWC}$-classes. The interquartile range within $5 \mathrm{~m}$ sections is generally very well represented by the minima and maxima of three values $(95 \%$ within $\pm 0.5 \mathrm{mWC}$-class, Fig. 10d-f shows the results for the measurements at $100 \mathrm{~cm}$ distance). With an increase in measurement spacing, the devation between $\theta_{5 \mathrm{~m}}$ and $\theta_{\mathrm{m} 3}$ was smaller and the minima and maxima of the three measurements tend to fall outside the interquartile range of $5 \mathrm{~m}$ crosssections. The recorded snow wetness differed less from $\theta_{5 \mathrm{~m}}$ if $\theta_{\mathrm{m} 3}$ was used rather than just one measurement $(p<0.05)$. 


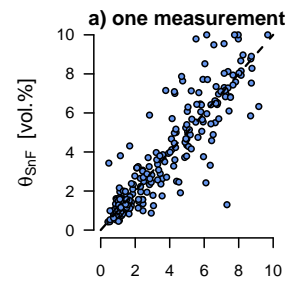

$\theta_{5 \mathrm{~m}}[\mathrm{vol} . \%]$

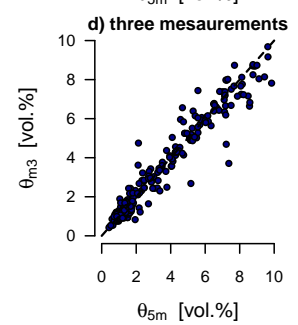

b)
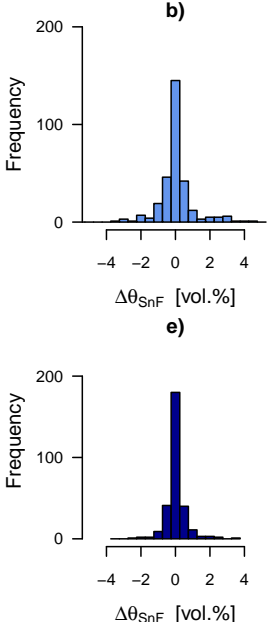

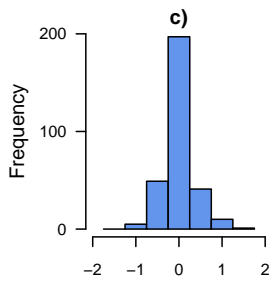

$\Delta \mathrm{mWC}$ class

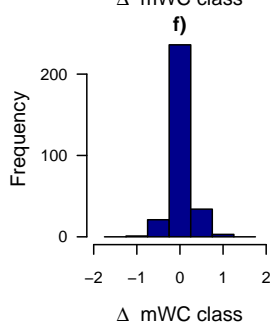

Fig. 10. Comparison between measurement samples and the median of a $5 \mathrm{~m}$ cross-section at a certain depth $\theta_{5 \mathrm{~m}}$. Upper row plots (a-c) show the comparison for one randomly selected measurement to $\theta_{5 \mathrm{~m}}$, lower row plots (d-f) compare the median of three measurements $\left(\theta_{\mathrm{m} 3}\right)$ observed at $1 \mathrm{~m}$ horizontal distance to $\theta_{5} \mathrm{~m}$. Scatterplots show the absolute values (a, d), the histograms the difference between $\theta$-values $(\Delta \theta$, plots (b) and (e)) and the difference in wetness classes $(\triangle \mathrm{mWC})$ using the international classification (Fierz et al., 2009, plots $(\mathbf{c}, \mathbf{f}))$.

Table 4. Deviation between median measured water content in $5 \mathrm{~m}$ cross-sections $\theta_{5 \mathrm{~m}}$ : if one measurement is done $\theta_{1}$ and to median water content if three measurements are done $\theta_{\mathrm{m} 3}$ at regular horizontal spacings of $50-200 \mathrm{~cm}$.

\begin{tabular}{rrrr}
\hline deviation from $\theta_{5 \mathrm{~m}}$ & $\theta_{1}$ & $\theta_{\mathrm{m} 3}-50 \mathrm{~cm}$ & $\theta_{\mathrm{m} 3}-200 \mathrm{~cm}$ \\
\hline$>0.5$ vol. $\%$ & $33 \%$ & $25 \%$ & $15 \%$ \\
$>1$ vol. $\%$ & $18 \%$ & $10 \%$ & $5 \%$ \\
$>2$ vol. $\%$ & $8 \%$ & $2 \%$ & $2 \%$ \\
\hline
\end{tabular}

\subsection{Temporal evolution of snowpack wetness}

The evolution of snowpack wetness during spring 2010 for southerly aspect slopes above tree-line is shown in Fig. 11 and Fig. 12. The snowpack was shallow with snow depth often less than $1 \mathrm{~m}$ and dominated by soft, coarse-grained faceted layers due to the relatively dry winter with sustained cold periods. The snowpack was predominantly dry and cold with snow temperatures mostly below $-1{ }^{\circ} \mathrm{C}$ on 18 March (Fig. 11a). Water infiltration was slow the following day too (Fig. 11b, c). On 20 March two grids were measured: the first at higher elevation showed a relatively dry snowpack with first weak flow channels (Fig. 11d), while the second, measured later in the afternoon and at lower elevation, was already moist to the ground (Fig. 12a). Four days later, on 24 March the snowpack was moist or wet throughout (Fig. 12b). This first wetting of the snowpack coincided with
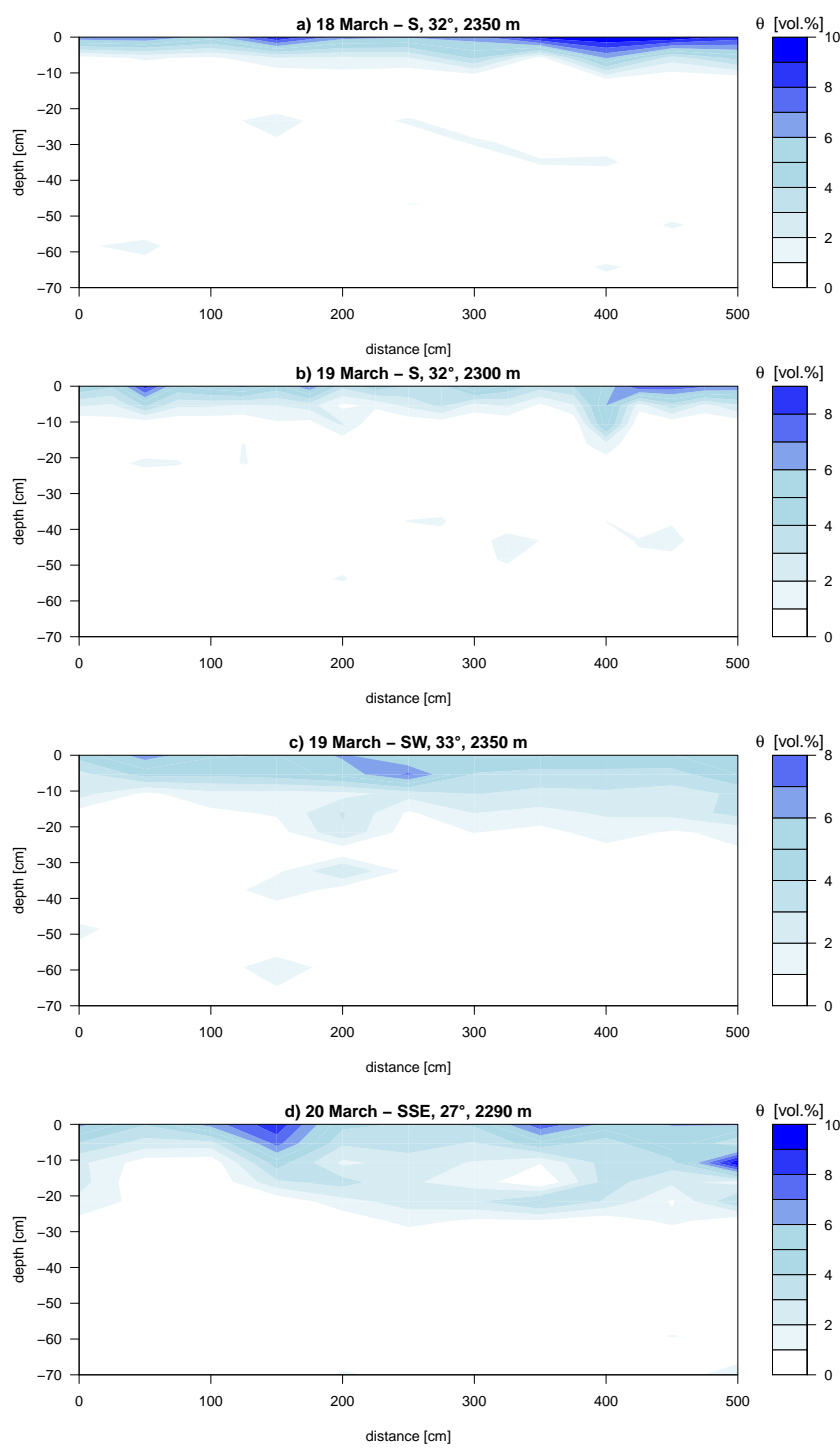

Fig. 11. State of snow wetness, 18-20 March 2010 in the beginning of the melt phase. Contour plots showing cross-sections of snow wetness $(\theta)$ to a depth of up to $70 \mathrm{~cm}$ over $5 \mathrm{~m}$ wide areas across the slope. All observations were observed in shallow snowpack areas at similar elevations (2000-2300 m) in southerly aspect slopes (SE, S, SW). $\theta$, measured with the Snow Fork, is corrected by -0.8 vol. \% (this corresponds to the median offset in dry snow). $\theta$-values greater than $10 \mathrm{vol} . \%$ are shown as $10 \mathrm{vol} . \%$.

wide-spread wet snow avalanching in the region of Davos (Fig. 3). A cold period with new snow (Fig. 12c) was followed by further melting (Fig. 12d). Subsequent avalanching from southerly aspect start zones was minor and related to shallow failures of the surface snow. 

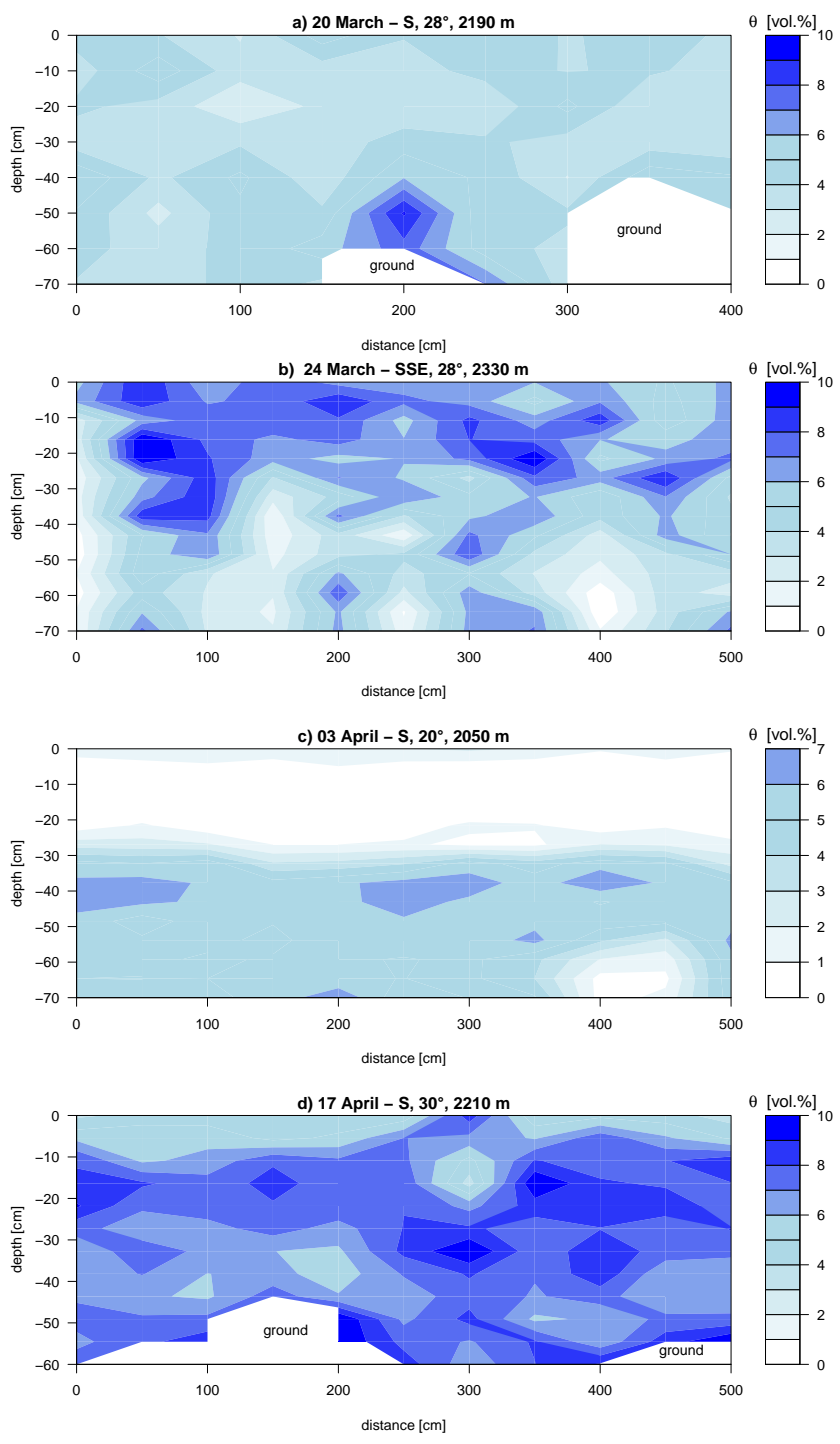

Fig. 12. Evolution of snow wetness during melting from 20 March till 17 April 2010. Contour plots showing cross-sections of snow wetness $(\theta)$ to a depth of up to $70 \mathrm{~cm}$ over $5 \mathrm{~m}$ wide areas across the slope. All observations were observed in shallow snowpack areas at similar elevations (2000-2300 m) in southerly aspect slopes (SE, S, $\mathrm{SW}) . \theta$, measured with the Snow Fork, is corrected by -0.8 vol. $\%$ (this corresponds to the median offset in dry snow). $\theta$-values greater than $10 \mathrm{vol} . \%$ are shown as $10 \mathrm{vol} . \%$.

\section{Discussion}

\subsection{Measurement methods and sampling strategy}

Two dielectric instruments were used to measure the liquid water content of snow: the Finnish Snow Fork and the Denoth meter. As in previous studies, the measured water content correlated well. However, the Snow Fork showed consistently higher values. This offset was most obvious in cold, dry snow, where the Denoth meter provided more likely esti- mates of water content. We found that one particularly useful feature of the Snow Fork is its long arm allowing measurements at depth without previously disturbing the water flow by digging a snow-pit. Although the Denoth instrument samples a 7.5 times larger measurement volume than the Snow Fork, we did not note significant effects on the variability of adjacent measurements. Our measurement methods do not allow a conclusive interpretation on the accuracy of the measured water content.

We have not investigated the effect impurities, such as soot or dust, or acid components have on the permittivity of the ice. We are aware, however, that such impurities exist and that these also influence permittivity measurements (e.g. Fujita et al., 1992). As our observations were conducted away from industrial areas we can only suspect that these effects will be relatively small. In the Swiss Alps, visual contamination of the snowpack is most frequently observed following strong southerly airstreams, when dust particles originating from the Sahara desert may color the snow surface reddish, or when snow algae is present. However, during the measurement campaign we could neither observe snow algae nor dust layers in the snowpack.

The water content distribution or the detection of lateral flow patterns in a snowpack may be best measured using the vertical measurement mode (Fig. 4c). It should be considered that the water content is measured over the length of the sensor $(75 \mathrm{~mm})$ and thinner layer specific observations are not possible. The horizontal or vertical wetness measuring cause only small disturbances in the snowpack; yet they are still destructive to the snow sample. Truly non-destructive methods like the ground penetrating radar looking upward from the snow-soil interface (GPR, Heilig et al., 2009) might be better suited to monitor changes in snow wetness in the same location.

The estimation of liquid water content in the field is difficult, even for experienced observers. When estimating the wetness of snow layers by hand test, it is important to observe stratigraphic layers always on a shaded side-wall of a snowpit (WSL, 2008). Snow temperature measurements may be an indicator of dry snow, although small amounts of liquid water have been measured in snow in temperatures below $0^{\circ} \mathrm{C}(\theta<1$ vol. \%, this study, also Kattelmann and Dozier, 1999). An additional help in the field may be the fact that snow wetness seldom exceeds 8 vol. \% in natural snow (Martinec, 1991b; Fierz and Föhn, 1994; Kattelmann and Dozier, 1999). Layers which contain water contents greater than 8 vol. \%, are normally relatively thin (as for instance above capillary barriers) or may be observed in vertical flow paths (as in Fig. 5). Thus, in freely draining snow, estimated snowpack wetness would be expected to lie mostly in the dry, moist or wet range.

As with other observed parameters like the hardness of snow layers, the hand test often provides information on relative differences rather than absolute values. Thus, estimated snow wetness must not be interpreted strictly according to the 
international guidelines but should be understood as an indication only (Fierz and Föhn, 1994). Expanding on a previous study (Martinec, 1991b), we investigated the effect of layer characteristics like hardness or grain shape on snow wetness estimation. It seems that it is more difficult to correctly estimate the wetness in layers consisting of melt-freeze particles. The liquid water content of melt-freeze-crusts undergoing melting is particularly hard to estimate. We assume that the reason for this is the larger range of snow wetness $(\theta 0-10 \mathrm{vol} . \%)$ and hardness. In particular at low water content when the ice matrix is still frozen for the most part, water cannot be seen using a magnifying lens and the squeeze test is not suitable in such hard layers. While layer hardness, grain shape and size may unconsciously influence wetness estimates, we were unable to quantify these effects. In cases where it is necessary to quantitatively interpret the estimated wetness, we propose a rough guide which is based on the study by Martinec (1991b) (Table 5).

Additionally to methodical aspects, small-scale spatial aspects should be considered when recording snow wetness in point locations. Due to a lack of data at greater spatial distances than $5 \mathrm{~m}$, we can only assume that a $5 \mathrm{~m}$ wide crosssection is a good representation of the snowpack wetness in a given slope and that the median water content and interquartile range are robust indicators of snow wetness at a certain snow depth. In particular in a partially wet snowpack, measuring (for instance) three wetness profiles at distances greater than $50 \mathrm{~cm}$ will provide a robust estimate of snow wetness and enhance the quality of wetness recordings using dielectric methods.

\subsection{Monitoring the advancement of the wetting front}

The measurements of snowpack wetness during spring 2010 were conducted on slopes of all aspects (illustrated for southerly aspects in Fig. 11 and 12). This information was available for the SLF avalanche warning team during the March melt-phase and was considered as very helpful to assess the advancement of the wetting front. However, for operational purposes it would be of advantage if continuous, real-time information from potential avalanche slopes would be available. In some avalanche forecasting operations, for instance in the maritime climate of Snoqualmie Pass (USA, Stimberis and Rubin, 2009) and the Milford Road area (New Zealand, Carran et al., 2002) snow temperature and water outflow measurements are used operationally to assess the advancement of the wetting front. Currently, in Switzerland, snow temperature is measured mostly at automatic weather stations in flat study plots. However, it would be very useful for avalanche forecasting purposes if such realtime snowpack information would be available from potential avalanche slopes.

The first significant period of water infiltration into the lower parts of the snowpack coincided with intense avalanche activity in both the springs of 2009 and 2010. It is
Table 5. Proposition of interpretation of manually estimated water content (hand test as per guidelines WSL, 2008; Fierz et al., 2009). The proposition from Martinec (1991b) $\left(\theta_{\text {Martinec }}, n=518,9\right.$ observers) is compared to our study $(\theta, n=314,4$ observers). This interpretation may apply only to experienced observers estimating the liquid water content. $\theta$, measured with the Snow Fork, is corrected by -0.8 vol. $\%$.

\begin{tabular}{lrrr}
\hline $\begin{array}{l}\text { Hand test } \\
(\mathrm{mWC})\end{array}$ & Signature & $\begin{array}{r}\theta_{\text {Martinec }} \\
\text { [vol. \%] }\end{array}$ & $\begin{array}{r}\theta \\
\text { [vol. \%] }\end{array}$ \\
\hline Dry & 1 & $<0.5$ & $<0.5$ \\
Moist & 2 & $0.5-2$ & $0.5-2$ \\
Wet & 3 & $2-4$ & $2-4.5$ \\
Very Wet & 4 & $4-5$ & $4.5-6$ \\
Slush & 5 & $>5$ & - \\
\hline
\end{tabular}

of note that very wet horizontal layers, as in Fig. 5, were absent during the avalanche cycle in spring 2010 . We suspect that this is due to the snowpack structure, which contained few spatially expanded possible capillary barriers, like fineover-coarse grained layer boundaries. Also, clear patterns of larger vertical flow paths could not be observed.

\subsection{Qualitative description of the wetness of a snowpack}

As we have discussed before, the reliable estimation and measurement of snow wetness in the field is difficult. Temporal changes in the amount and distribution of liquid water in snow may occur rapidly. Therefore, it might be more practical and sufficient for avalanche forecasting and snow hydrology purposes to use a very general description of the wetness of a snowpack. Based on our observations, we propose five wetness profile types, which may be based on estimated or quantitatively measured water content. It could also be based simply on the distinction between dry and not-dry snow. We suggest that surface layers are not included in this classification as these show significant changes during the diurnal freeze-melt-cycles. The classification incorporates both vertical and horizontal wetness distribution.

The snowpack is dry before the melt-phase (Fig. 13, type 1). With continued input of liquid water through melt or rain, snowpack wetness increases. Initially, only a part of the snowpack is wet while some areas remain dry. The wetting may follow a "step-and-fill-pattern" (Conway and Benedict, 1994) (Fig. 13, type 2). Often, in a snowpack consisting predominantly of coarse-grained temperature-gradient snow, preferential flow fingers will penetrate the snowpack relatively quickly and water may temporarily flow laterally along capillary barriers (Marsh, 1988) (Fig. 13, type 3). At this stage, first water outflow at the base of the snowpack may be observed. With continued water infiltration the snowpack will be fully wet and homogenize (Jordan et al., 2008) (Fig. 13, type 4). Once drainage channels are well established, water outflow will respond quickly to additional input 


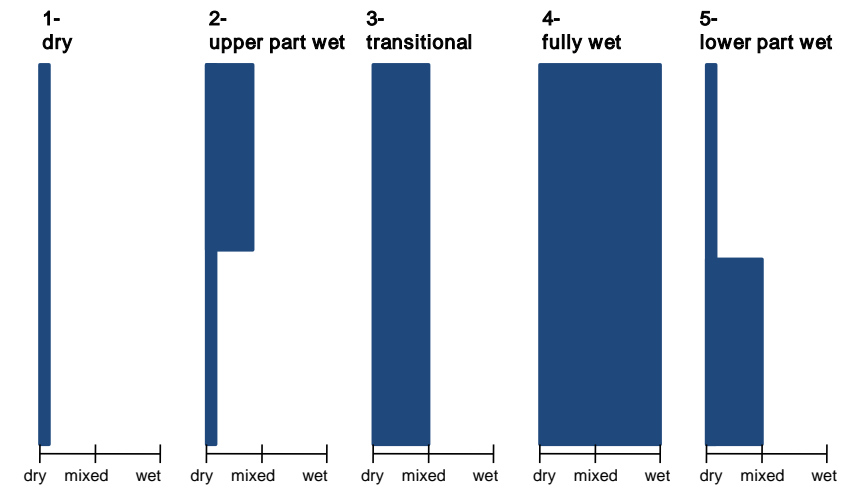

Fig. 13. Wetness classification incorporating vertical and horizontal water content distribution. The x-direction shows the percentage of the snow which has been wetted, where dry/wet is fully dry or fully wet and mixed consists of both dry and wet regions. The y-direction shows the vertical distribution of snow wetness $(50-100 \mathrm{~cm})$. Diurnal changes occur mostly within the upper-most $10-15 \mathrm{~cm}$ of the snowpack and are not considered in this classification.

of melt-water (Carran et al., 2002). A special case is the situation that the snowpack begins to refreeze or new snow falls on an already wet snowpack after a melt-event (Fig. 13, type 5).

We propose this very simplified classification and are aware that more variations will exist. However, such a basic classification can facilitate the description of the snowpack wetness, in particular for hydrological and avalanche forecasting purposes. One advantage of such a classification is that the distinction between dry and not dry snow will likely be more accurate than the estimated wetness classes. Additionally, it describes the spatial wetness distribution which currently is not included in a snow profile observation. The spatial wetness distribution may be observed when excavating a snow pit for avalanche forecasting or snow hydrological purposes.

\section{Conclusions}

Methodical, spatial and temporal aspects must be considered when observing snow wetness in the field and interpreting wetness information.

The method of estimating the liquid water content using the hand test can not be regarded as a reliable method to record snow wetness if absolute values are of interest (research question 1). If it is necessary to quantitatively interpret the qualitative wetness recordings, Table 5 may provide a rough aid for conversion. The hand test is more suited to record the relative wetness differences within one profile (Fierz and Föhn, 1994) and the difference between dry and not dry snow. Our study expands previous research (Martinec, 1991b) by incorporating snow layer properties like hardness, grain shape and size. Differences in correctly esti- mated wetness existed in layers consisting of different grain shape, however no conclusive results were obtained (research question 2).

Dielectric measurement methods are generally a more reliable indicator of snow wetness at a given point within the snowpack. If the measured liquid water content is low (less than approximately $1.0-1.5 \mathrm{vol} . \%$ ), the measured wetness should be interpreted with caution. In such cases, we believe, that the snow could be either dry or contain small quantities of liquid water. If the presence of very wet layers is of interest and an instrument like the Snow Fork is available, measurements should be undertaken before excavating a snow pit. Otherwise, only small differences existed between measurements made on the shaded side-wall of a snow-pit or in a previously undisturbed snowpack (research question 3). Vertical measurements of snow wetness using the Snow Fork are an efficient way to record spatial distribution of snow wetness.

As for dry snow observations, site selection is important to observe representative information. To obtain representative wetness information, slope aspect and inclination, elevation and the distance to rocky areas should be considered. Still, the small-scale spatially heterogeneous distribution of dry and wet areas within the snowpack may lead to unrepresentative results. Our observations showed that approximately every fifth to tenth wetness profile was a poor representation of the surrounding snow wetness (research question 4). Therefore we propose to observe several measurements at horizontal distances greater than $50 \mathrm{~cm}$. Because our measurement extent was limited to $5 \mathrm{~m}$, we can not give conclusive results on spatial correlation of liquid water content. As far as we are aware, this is the first study quantifying the variability of liquid water distribution in a snowpack at scales up to $5 \mathrm{~m}$.

Based on our observations on spatial variability in snow wetness, we propose a snowpack-wetness classification. We see this as a first step towards the development of a wet snow classification scheme as exists for the assessment of dry snow profiles (Schweizer and Wiesinger, 2001). Incorporating additional snowpack properties like the state of wet snow metamorphism (grain shape), snow layering and snow temperature may improve the value of such a classification for avalanche forecasting purposes and could also assist in flood forecasting during snow melt periods.

Point observations in wet snow provide important information on the state of wetting of a snowpack, which influences wet snow stability. However, as water infiltration in snow is a fast process, timing of observations is critical. Therefore, for operational avalanche forecasting purposes it is necessary to continuously observe parameters like snowpack temperatures, liquid water content or water outflow not only in flat study plots, but also in potential avalanche slopes. This is operationally done in some forecasting operations (for instance in the US or New Zealand).

To our knowledge, there is currently no reliable, economical and practical alternative available to the hand test to 
measure snow wetness in the field. Therefore, we propose that future research should investigate possibilities of developing a practical, hand-held instrument to quantitatively measure the liquid water content in snow (similar to a digital thermometer). Further, it would be advantageous to know the distribution of the liquid water content at the slope-scale to allow better interpretations of point observations in wet snow.

Acknowledgements. We greatly thank Adrian Räz, who assisted in the field. Christoph Mitterer shared important field information. $\mathrm{He}$, as well as Thomas Stucki and Stephan Harvey provided valuable comments which helped improve the manuscript. We thank the editor Andrew Klein, one anonymous reviewer and Howard Conway for their very helpful feedback on this paper.

Edited by: A. Klein

\section{References}

Armstrong, R.: Wet snow avalanches, in: Avalanche Research and Snow Characteristics, edited by: Armstrong, R. and Ives, J., San Juan Mountains, Colorado, University of Colorado INSTAAR, Occasional paper 19. p. 256, Boulder, CO. 67-82, 1976.

Blöschl, G: Scaling issues in snow hydrology, Hydrol. Proc., 13, 2149-2175, 1999.

Brun, E.: Investigation on wet-snow metamorphism in respect of liquid-water content, Ann. Glaciol., 13, 22-26, 1989.

Carran, W., Hall, S., Kendall, C., Carran, A., and Conway, H.: Snow temperatures and water outflow during rain and melt; Milford Highway, New Zealand, in: Proceedings International Snow Science Workshop, Big Sky, Montana, 2002, 173-177, 2002.

Colbeck, S.: Water flow through heterogeneous snow, Cold Reg. Sci. Technol., 1, 37-45, 1979.

Colbeck, S.: An Overview of Seasonal Snow Metamorphism, Rev. Geophys., 20, 45-61, 1982.

Colbeck, S.: A review of sintering in seasonal snow, US Army Cold Regions Research and Engineering Laboratory Report, 9710, 1997.

Coléou, C. and Lesaffre, B.: Irreducible water saturation in snow: experimental results in a cold laboratory, Ann. Glaciol., 26, 6468, 1998.

Conway, H. and Benedict, R.: Infiltration of water into snow, Water Resour. Res., 30, 641-650, 1994.

Conway, H. and Raymond, C.: Snow stability during rain, J. Glaciol., 39, 635-642, 1993.

Crawley, M.: The R book, John Wiley \& Sons Ltd., 1 edition, 1997.

Denoth, A.: An electronic device for long-term snow wetness recording, Ann. Glaciol., 19, 104-106, 1994.

Fierz, C. and Föhn, P.: Long-term observation of the water content of an Alpine snowpack, in: Proceedings International Snow Science Workshop 1994 Snowbird, Utah, USA, 117-131, 1994.

Fierz, C., R. L., A., Durand, Y., Etchevers, P., Green, E., McClung, D., Nishimura, K., Satyawali, P., and Sokratov, S.: The International Classification for Seasonal Snow on the Ground, IHP-VII Technical Documents in Hydrology N83, IACS Contribution N1, UNESCO-IHP, Paris, 2009 .
Frolov, A. and Macharet, Y.: On dielectric properties of dry and wet snow, Hydrol. Process., 13, 1755-1760, 1999.

Fujita, S., Shiraishi, M., and Mae, S.: Measurement on the dielectric properties of acid-doped ice at $9.7 \mathrm{Ghz}$, Geosci. Remote Sens., 30, $799-803,1992$.

Gupta, R.P., Haritashya, U. K., and Singh, P.: Mapping dry/wet snow cover in the Indian Himalayas using IRS multispectral imagery, Remote Sens. Environ., 97(4), 458-469, 2005.

Heilig, A., Schneebeli, M., and Eisen, O.: Upward-looking groundpenetrating radar for monitoring snowpack stratigraphy, Cold Reg. Sci. Techn., 59(2-3), 152-162, 2009.

Jones, E., Rango, A., and Howell, S.: Snowpack liquid water distributions using freezing calorimetry, Nord. Hydrol., 14, 113-126, 1983.

Jordan, R.: Effects of capillary discontinuities on water flow and water retention in layered snowcovers, in: Proceedings of Snowsymp, International Symposium on Snow, Manali, India, 1994, 157-170, 1994.

Jordan, R., Albert, M., and Brun, E.: Physical processes within the snow cover and their parametrization, in: Snow and climate: physical processes, surface energy exchange and modeling, edited by: Armstrong, R. and Brun, E., Cambridge University Press, 12-69, 2008.

Kärkäs, E., Martma, T., and Sonninen, E.: Surface snow properties and stratigraphy during the austral summer in western Dronning Maud Land, Antarctica, Polar Res., 24, 55-67, 2005.

Kattelmann, R.: Wet Slab Snow Instability, in: Proceedings International Snow Science Workshop, 24-27 Oct 1984, 102-108, 1985.

Kattelmann, R. and Dozier, J.: Observations of snowpack ripening in the Sierra Nevada, California, USA, J. Glaciol., 45, 409-416, 1999.

Louge, M., Foster, R., Jensen, N., and Patterson, R.: A Portable Capacitance Snow Sounding Instrument, Cold Reg. Sci. Technol., 28, 73-81, 1998.

Lundberg, A., Granlund, N., and Gustafsson, D.: "Ground Trut" snow measurements - review of operational and new measurement methods for Sweden, Norway, and Finland, in: Proceedings 65th Eastern Snow Conference, Fairlee (Lake Morey), Vermont, USA, 215-237, 2008.

Marsh, P.: Grain growth in a wet Arctic snow cover, Cold Reg. Sci. Technol., 14, 23-31, 1987.

Marsh, P.: Flow fingers and ice columns in a cold snowcover, in: Proceedings Western Snow Conference, 18-20 April, 1988, Kalispell, Montana, 105-112, 1988.

Marshall, H., Conway, H., and Rasmussen, L.: Snow densification during rain, Cold Reg. Sci. Technol., 30, 35-41, 1999.

Martinec, J.: Flüssiger Wassergehalt in der Schneedecke im Gebiet Davos-Weissfluhjoch, April-Juni 1988 (Liquid water content in the snowpack in the region of Davos-Weissfluhjoch, AprilJune 1988), internal report 663 (unpublished), WSL Institute for Snow and Avalanche Research SLF, Davos, 1999a.

Martinec, J.: Schneefeuchtigkeit mit dem Denoth-Gerät im Vergleich mit dem Handtest, Messungen 1989, 1990 (Snow wetness with the Denoth-meter in comparison to the hand test, measurements 1989, 1990), internal report 667 (unpublished), WSL Institute for Snow and Avalanche Research SLF, Davos, 1999b.

Mess-Systemtechnik, S.: Snow Pack Analyser (SPA) zur Bestimmung des Schneewasseräquivalents und des 
Flüssigwasseranteils, Sommer GmbH \& Co. KG, Koblach, Austria, available at: http://www.sommer.at, p. 10, 2010.

Mitterer, C., Hirashima, H., and Schweizer, J.: Wet-snow instabilities: comparison of measured and modelled liquid water content and snow stratigraphy, Ann. Glaciol., accepted, 2010.

Moldestad, D.: Characteristics of liquid water content and snow density in a cross-country race ski track, Bull. Glaciol. Res., 22, 39-49, 2005.

R: R A Language and Environment for Statistical Computing, R Foundation for Statistical Computing, Vienna, Austria, ISBN 3-900051-07-0, 2009.

Raymond, C. and Tusima, K.: Grain coarsening of water saturated snow, J. Glaciol., 22, 83-105, 1979.

Schneebeli, M.: Development and stability of preferential flow paths in a layered snowpack, IAHS-AIHS Publ. 228, 89-96, 1995.

Schweizer, J. and Wiesinger, T.: Snow profile interpretation for stability evaluation, Cold Reg. Sci. Technol., 33, 179-188, 2001.

Sihvola, A. and Tiuri, M.: Snow fork for field determination of the density and wetness profiles of a snow pack, IEEE T. Geosci. Remote, GE-24, 717-721, 1996.

Stein, J., Laberge, G., and Lévesque, D.: Measuring the dry density and the liquid water content of snow using time domain reflectometry, Cold Reg. Sci. Technol., 25, 123-136, 1997.

Stimberis, J. and Rubin, C. M.: Glide avalanche response to an extreme rain-on-snow event, Snoqualmie Pass, Washington, USA, in: Proceedings International Snow Science Workshop 2009, Davos, Switzerland, 301-305, 2009.
Techel, F. and Pielmeier, C.: Wet snow diurnal evolution and stability assessment, in: Proceedings International Snow Science Workshop, edited by: Schweizer, J. and Van Herwijnen, A., 27 September to 2 October 2009, Davos, Switzerland., 256-261, 2009.

Techel, F., Pielmeier, C., and Schneebeli, M.: Microstructural resistance of snow following first wetting, Cold Reg. Sci. Technol., 65, 382-391, 2001

Toikka: Snow Fork - manual, Ins.toimisto Toikka Oy, Espoo, Finland, p. 20, 2008

Toikka: Snow Fork - a portable instrument for measuring the properties of snow., Ins.toimisto Toikka Oy, Espoo, Finland, http://www.toikkaoy.com/, p. 2, 2009

Waldner, P., Schneebeli, M., Zimmermann, U., and Flühler, H.: Effect of snow structure on water flow, Hydrol. Process., 18, 12711290, 2004.

Wankiewicz, A.: A review of water movement through snow, in: Proceedings of the modeling of Snow Cover Runoff, edited by: Colbeck, S. and Ray, M., CRREL Special Report, 222-252, 1979.

Warren, S. G. and Wiscombe, W. J.: Dirty snow after nuclear war, Nature, 313, 467-470, 1985.

Williams, M., Sommerfeld, R., Massman, S., and Rikkers, M.: Correlation lengths of meltwater flow through ripe snowpacks, Colorado Front Range, USA, Hydrol. Process., 13, 1807-1826, 1999.

WSL: SLF-Beobachterhandbuch: Regionale Beobachter, Hangprofiler, Geländebeobachter, WSL Institute for Snow and Avalanche Research SLF, Davos, 2008. 